\title{
The Importance of Big Data Analytics in Business: A Case Study
}

\author{
Hiba Alsghaier ${ }^{1}$, Mohammed Akour ${ }^{2}$, Issa Shehabat ${ }^{3}$, Samah Aldiabat ${ }^{3}$ \\ ${ }^{1}$ Computer Information Systems Department, Yarmouk University, Irbid, Jordan \\ ${ }^{2}$ Software Engineering Department, Yarmouk University, Irbid, Jordan \\ ${ }^{3}$ Management Information Department, Yarmouk University, Irbid, Jordan
}

Email address:

hibaal_sghaier@yahoo.com (H. Alsghaier), Mohammed.akour@yu.edu.jo (M. Akour), ishehabat@yu.edu.jo (I. Shehabat), sdiabat_1@yahoo.com (S. Aldiabat)

To cite this article:

Hiba Alsghaier, Mohammed Akour, Issa Shehabat, Samah Aldiabat. The Importance of Big Data Analytics in Business: A Case Study. American Journal of Software Engineering and Applications. Vol. 6, No. 4, 2017, pp. 111-115. doi: 10.11648/j.ajsea.20170604.12

Received: August 21, 2017; Accepted: September 5, 2017; Published: October 2, 2017

\begin{abstract}
Companies all over the world try to get the benefits from accessing to information that is available in social media to improve their performance and increase their revenue, processing heterogeneous type of data to extract the valuable data is a problem that many organizations try to solve. One of the most important trends is in general known as "Big Data", technology for Storing, Processing and analyzing data, companies are Managing data in order to use it in new levels and direct decision makers to make agile decisions in real time, Big Data trend have the capability to guide a revolutionary transformation in research, invention, and business marketing. In this research we highlight some aspects of Big Data and its importance on organizations' business performance and how companies can use the famous open source platform Hadoop to process data to gain the competitive advantage.
\end{abstract}

Keywords: Big Data, Big Data Analytics, Business Improvement, Hadoop, Data-Driven Companies

\section{Introduction}

Big data became the most famous event in the last decade, many organizations like Google, yahoo, eBay, Facebook and twitter concern about big data since the beginning of it is shown on the business scene [1]. Big data is higher and richer data that shows more details about behaviours, activities and events that happened all around, so analytics of these big data give the access to variety and different types of data from huge recourses with less response time [2].

Companies that collect data might be used it to produce new income streams. So that companies must begin with a business reason for analytics after that detect which form of analytics they want in order to determine how data will be collected, sorted, and processed for the previous selected analytics form [3].

Since organizations that didn't have the traditional forms or sources of infrastructure, they didn't face the problem of incorporating the old technology with big data analytics.

However, Analytics big data get along with data analytic in other types. For example Hadoop, which is software that sort massive types of data, does it is work beside the mainframes of IBM. The rapid flow of data means that it should be arranged sorted and processed quickly [1].

Some companies who concern about telecommunications have shrewdness into the volume and speed of high road traffic got the benefit from information collected from the power of big data, another example Disney land gets the benefit from big data analytics by introducing "magic wristbands" in their parks, these bracelets enhance the attention of visitors around the park [4]. Amazon can predict what the customer prefers to buy and introduce the products to them according to their preferences.

The opportunities that are related into data analysis in many organizations have generated an important interest in business intelligence, which is sometimes point to the techniques and technologies that help to produce better understand ability of the market and also make decisions in accurate time [5], also 
organizations conclude the biggest value from big data when workers are free to explore their analyses. Establishing this type of environment leads the IT work team to change from a serving into enabling models [4].

Big Data is unexpectedly everywhere and everyone try to collect and analyze it, also collecting money by using its power. when we are talking about collecting and analyzing billions of search engines queries and billions of Smartphone records to determine signals of terrorist attacks and activities, or billions of airline situations to select the suitable time for buying tickets, big data is the state of these cases. By merging the power of new computing trends with the numerous digital data, it undertake to solve practically any problems like crimes, health care and other problems just by processing large amounts of information or perform operations of great complexity, especially by computer.

\subsection{Research Questions}

What is the benefit from big data analytics?

How organizations can collect numerous amounts of data?

How organizations can employ big data analytic to enhance their business and gain a competitive advantage?

\subsection{Research Significance}

Big data analytics aid organizations to utilize their data and employ it to find new opportunities. Furthermore it leads to intelligent business moving ahead, more effective operations, high profits and satisfied customers. So organizations should deal with big data analytics seriously and smartly to enhance and improve its development issues.

\section{Background}

The beginning and growth of big data was on early 2011, although it is still in the early stages of development it is still suffering of many problem and programming difficulty issues, it is so obvious that utilizing its capabilities gives full business services. Big data is an expression added to data sets that are so huge where usually software tools cannot hold, manage, and process them during an acceptable time in a cost effective manner[6], The enforcement of big data is widely accepted by many industries and companies, which leads them to improve their business processes [7]. So big data has imparted golden opportunity to the universal market, every part of industry is trying to evaluate the higher possibilities to gain and analyze information to take better decisions, much data means much more use-cases, more use-cases leads to more illustration of business evaluation which ultimately leads to best business decision making. This scenario will lead to much profit, by changing the traditional approach of managing data into helpful new approaches [8].

\section{Literature Review}

\subsection{Big Data Analytic's Benefits Toward Business}

Technology for holding, analyzing data is broadly available at lower cost points. But firms are taking data in order to use it in new levels, using information technology to shore accurate, stable business experimentation that direct decision makers and to examine outputs, business models, and regeneration in customer experience sometimes, the new trends help firms to make decisions in the real time. These trends have the possibility to guide a revolutionary transformation in research, invention, and business marketing. Some companies, like Amazon, eBay, and Google, considered as early commandants, examining factors that control performance to define what raise sales revenue and user interactivity. Finance establishments are strong experimenters as well as principal one who keep to emend its methods for segment credit card customers. Brick and mortar companies are also using big data for rigid testing the capability to advise customer data by gathering transactional data from millions of customers by using a loyalty card, the collected information is used to analyze new opportunities, for example, how to achieve the most efficacious promotions for particular customer parts and to cognize decision on pricing, advancement other firms using data mining to collect information from social media, southwest airlines, Ford motor and Pepsico, analyze consumer posts on social media like Facebook and Twitter to standard the instantaneous influence on campaign and to examine consumer opinion about their products. Using big data as fundamental factor of making decision which need new capability, most firms are far away from accessing all data resources [13].

Companies in various sectors have acquired crucial insight from the structured data collected from different enterprise systems and anatomize by commercial database management systems. Companies must not let previous existing data warehouse and present business intelligence processes rein the organization back. Reengineering processes maybe used within the organizations to merge big data analytics to employ the strengths of big data and harvest the advantages of it. Big data analytics need business processes to modify and stratify with the IT infrastructure of the organization to shore the business actions. data analytics influence on infrastructure components, so companies must concentrate on this now and later on to achieve the competitive advantage [14].

\subsection{Utilizing Hadoop in Big Data Analytics}

Hadoop is "an open source software platform that enables processing of large data sets in a distributed computing environment", the authors in [9] discussed some concepts according to big data, the rules for building, organizing and analyzing huge data-sets in the business environment, they offered 3 architecture layers and also they indicate some graphical tools to explore and represent unstructured-data, the authors specified how the famous companies could improve their business for example Google, Twitter and Facebook show their attention in processing big data within cloud-environment Many companies get the benefit from collecting and analyzing data from comments on social media. Zynga is a game maker who collected data from 
customer service and he used these collected data to design new version for his game. Another example is Caesars Corporation who analyzed health-insurance data for 65,000 employees and their families about how they used medicalservices and used these data to deal with specific drugs companies. The authors in [9] build a big-data infrastructure for their project; they presented a new database called "NoSQL" for storing big data, and implemented it on Hadoop for gathering structured and unstructured data. The first architecture layer designed to collect any type of data whether it is structured or unstructured the second one is processing the previous collected data using Hadoop and the last one is analyzing Big Data by using analytical business and modelling tools.

The organizations who concern about big data they need huge amount of data that is quantifiable, tools like Hadoop and high qualified staff with skills in science, privacy and understandability of business environment. Hadoop is document system, which permits capacity for whatever sort of the data, Hadoop goes by on the fly demonstrating of the data, which might be truly a chance to be imperative and at the same time coordinated and available for huge information, so analytics might improve those benefits of the business insights [10]. On the other hand the authors in [11] introduced a big-data-analytic technique which establish a business context in phrase of the significance level of a query their proposed model using Hadoop within a grocery market, the proposed technique consist of 3 steps, the first one is representing the business context by specifying the keywords that will be used in the query to collect data, the second one is collecting relevant data to the business context from all conceivable grocery and finally analyzing the final data, the query was "How were the customers experiences with fruit and vegetable purchased from the shop?" the answers are collected and analyzed using Hadoop, the results show that their technique basically increases the amount of the collected data and increase the revenue values [11]

Big data depend on the implementation and procedures of difficult manners comparing to small datasets. Problems with big data involve record, memorize, search and analyze. furthermore, in every analysis process new data will be produced sometimes big data analysis procedure include the extended data and computing models, an example of computing model is "MapReduce" which target on parallel processing of the big extended data which was utilized in many applications, like searching in DNA strings, the most popular implementation of the "MapReduce" is Hadoop framework which include diverse memory data processing, depending on this framework, huge big data can be processes quickly and efficiency [12].

\subsection{The Employment of Big Data Analytics on IBM}

Big data techniques improve operational effectiveness and efficiencies of generating great revenues in business. The effectiveness and Efficiency of these techniques have been analyzed in the literature review uses the point of view that it brings greater understanding of business value and develops business growth. Also the authors in [15] refer that companies are trying to reveal the answer to very basic questions that are important to adjust their business. Communication and distribution of information between different corporations is easy nowadays by using big data analysis and IT techniques. These organizations can collect data from their customers to enhance their business. for example IBM developed a cooperating and reacting methodology to help retired people, IBM implemented this methodology for retired people in Italy who need services like, healthcare and other emergency services this developed technology depends on sensors distributed within the home to measure heat, $\mathrm{O} 2$ level, clamminess, water and electricity, any abnormal thing in these patterns will alert the responsible service like fireman, paramedics or police according to the situation. This collaborative responsive technique has helped reduce assistance cost of retired people up to 30 percent and also it help to deliver the required in shorter time with less disbursement [15]. Another research developed by [16] who focused on commercial oriented-databases for extraction business aims, the author chose the database to support measuring important topics in industry with concern of big data the author show that specific types of companies may be classified into objective groups relating to big data many firms are interested in the big data analytics to improve their business for example IBM and Microsoft are prominent representatives. IBM represented many big data options that enable users to storing, managing, and analyzing data through various resources; it has a good rendering on business-intelligence also healthcare areas. Compared with IBM, also Microsoft showed powerful work in the area of cloud computing activities and techniques another example is Face-book and Twitter, who are collecting various data from user's profiles and using it to increase their revenue [16].

\subsection{The Performance of Data Driven Companies}

The major skeptic question that may pose most companies is "how the using of big data will improve business performance?" the press of the business is full of case studies that suppose of being a data driven, the problem is that no one takes the mentioned question seriously, to cover this gap, the authors in [17] let a team in a specific digital business center, work with McKinsey's and displayed a test hypothesis about driven- data companies if they are doing better performers the author carry out a structured interview with administrator of 330 public companies asking them about their technology, and management policies, and collect executed data by using the yearly reports and autonomous sources, the author found that an expansive concatenation of situations and approaches in all industries and the companies in the highest position of industry who use the data driven decision making on average, $5 \%$ are more productive and $6 \%$ are more profitable than other competitors, this different execution stick around strong after considering the contribution of capital, purchased services and labor.

Big data analytics can Improve airline agencies for example if an airplane land before the staff are ready, the 
travellers and crew are surly trapped, the a majority of US airlines get the benefit from the local study that $10 \%$ of flights have a 10 minute between the evaluated time for arrival and the real time arrival, the airlines depend on the flight industries, The aviator made these predictions through their last approach to airport, they have another demand on their time and attentiveness. As a solution, the airline turns out into Passur Airlines, as a provider of support- decision technology for the airline industries. At the beginning of 2001 Passur start showing their arrival predictions as a service called "RightETA". It calculate the times by consolidate aboveboard available information about weather, flights schedule, and another factors with data of company itself collected, include feed from networks of a radar station that is installed next of the airports to collect data from all the planes in the sky, Passur start with a few installations, by 2012 they collect a enormous range of data about all planes, that produce a huge amount of digital data. Moreover, the Passur keep all information that is collected, so they have multidimensional data span more than 10 years. Passur confirm that qualifying the airlines to know when their planes are going to land off and accordingly plan worth many billion dollars. The straightforward formula is by using the big data analytics will lead to best prediction, and best prediction produce best decision [17].

Big data analytics and Business intelligence are united fields which became widely significant in the business and academic area, companies are permanently trying to make insight from the extending the three V's ( variety, volume and velocity) to support decision making. Organizations focus on recognizing trends to gain competitive advantage and get the opportunities related to data analytics. However, researchers argued the leveraging technology benefits and the ability to make the best use of new agility trends, Insights from big data analytics have the possibility to enable business process oversight and measurement, reinforce quality management and the relationship with customers [18].

\section{Interpretations}

Big data analytics is a new trend that start to show on the scene in the last decade, many intelligent companies try to implement big data analytic to be in the race within the industrial environment, so the idea here how to be agile to implement big data analytic to improve business, many companies failed to obtain big data analytics because they didn't have the required infrastructure to implement Hadoop, other companies didn't consider the privacy licence by entering into unauthorized information.

The risk in utilizing of big data analytics is obviously the privacy aspects, not all the required information can be easily accessed, so that companies must consider the rules of taking information from other websites or from individual's private accounts. So the major question that companies ask is "How to be agile in using big data analytics?". The guide is pure, data driven decision lead to the best decisions which make administrator foster this fact, and companies that discover how to merge the expertise domain with data analytics will roll away from their competitor because Some companies maybe even don't dominate the required technologies to hold and analyze the priceless information, moreover, they didn't have the completely skill and procedures to collect data and extract value from huge amount of data.

The problem in utilizing Hadoop in big data analytics is the incorporation between Hadoop and the previous ERP systems of the organizations, a likely scenario in [9] point to an integrated architecture that integrates Big Data technologies in real systems, companies should be agile when they merge the old infrastructure with the new one.

Once Big data can used with respect of all the mentioned risks, companies will realize how much suddenly revenue will increase, and customer's services will continually scanned from billions of people, also it will help in forecasting and planning to reach best expectation in online sales, and the main benefit of big data is the competitive advantages that can be achieved by listening to the customers ideas and support their ideas by introducing to them what they really want.

\section{Research Gap}

The weakness in the environment of big data is large because of the lack in organization's skills and technologies, the lack of knowledge about big data and lack of experience in the big data analytics utilization, there are internally motives from managers into externally motives from the supply sides of big data. The weakness in the environment of big data lead to fill the gap in the presence of suitable technologies that lead to overcome the barriers discussed in the literature.

\section{Conclusion}

Exploitation of big data analytics in industrialization procedures can promote the agility and industrialization performance. The transmit toward big data analytics shore the performance predictors which allow decision makers to employ further data in taking account many actions when striving the organization goals, when organizations employ big data analytics, they can preferable predict already unpredictable things, and upgrade the process performance. Organization realize operational processes benefits by cost reduction, best operations plan, lower inventory levels, best organizational labor force and eliminate wasteful resources, also they influence improvements in operations efficiency. An organization big data analytics capabilities (like data resourcing, accessing, integrating, and delivering) and organizational factors (like big data analytics strategy) could speed up of efficient exploitation of big data analytics in processes and operations.

We might not say that every success organization will utilize big data to change decision making, but big data educate us to implement big data analytic to improve business in respect with all risks, big data analytics educate 
us to be in the race within new trend's environment.

\section{References}

[1] Davenport, H., and Jill, D. "Big data in big companies." International Institute for Analytics (2013).

[2] http://www.sas.com/en_us/whitepapers/iia-prescriptiveanalytics-107405.html

[3] Russom, P. "Managing big data." TDWI Best Practices Report, TDWI Research (2013): 1-40.

[4] Barnaghi, P, Amit, S, and Cory, H. "From Data to Actionable Knowledge: Big Data Challenges in the Web of Things [Guest Editors' Introduction]." IEEE Intelligent Systems 28.6 (2013): $6-11$.

[5] Chen, H, Roger HL Chiang, and Veda C. Storey. "Business Intelligence and Analytics: From Big Data to Big Impact." MIS quarterly 36.4 (2012): 1165-1188.

[6] Jiang, W. and Chai, H., 2016, July. Research on big data in business model innovation based on GA-BP model. In Service Operations and Logistics, and Informatics (SOLI), 2016 IEEE International Conference on (pp. 174-177). IEEE.

[7] Wang, Z. and Zhao, H., 2016, June. Empirical Study of Using Big Data for Business Process Improvement at Private Manufacturing Firm in Cloud Computing. In Cyber Security and Cloud Computing (CSCloud), 2016 IEEE 3rd International Conference on (pp. 129-135). IEEE.

[8] Sosna, M., Trevinyo-Rodríguez, R. N. and Velamuri, S. R., 2010. Business model innovation through trial-and-error learning: The Naturhouse case. Long range planning, 43(2), pp.383-407.

[9] Banica, L., \& Hagiu, A. (2015). Big Data In Business Environment. Scientific Bulletin-Economic Sciences, 14(1), 79-86.

[10] Alfouzan, H. I. Big Data In Business. International Journal of Scientific \& Engineering Research, Volume 6, Issue 5, May20151351 ISSN 2229-5518.

[11] Dinh, L. T. N., Karmakar, G., Kamruzzaman, J., \& Stranieri, A. (2015, December). Business context in big data analytics. In 2015 10th International Conference on Information, Communications and Signal Processing (ICICS) (pp. 1-5). IEEE.

[12] Sarnovsky, M., \& Paralic, J. (2015, November). Teaching big data analysis at Technical University in Kosice in business information systems study program. In Emerging eLearning Technologies and Applications (ICETA), 2015 13th International Conference on (pp. 1-6). IEEE.

[13] Bughin, J., Chui, M., \& Manyika, J. (2010). Clouds, big data, and smart assets: Ten tech-enabled business trends to watch. McKinsey Quarterly, 56(1), 75-86.

[14] Jha, M., Jha, S., \& O'Brien, L. (2016, June). Combining big data analytics with business process using reengineering. In Research Challenges in Information Science (RCIS), 2016 IEEE Tenth International Conference on (pp. 1-6). IEEE.

[15] Chaudhary, R., Pandey, J. R., \& Pandey, P. (2015, October). Business model innovation through big data. In Green Computing and Internet of Things (ICGCIoT), 2015 International Conference on (pp. 259-263). IEEE.

[16] Huang, Y., Youtie, J., Porter, A. L., Robinson, D. K., Cunningham, S. W., \& Zhu, D. (2016, October). Big Data and Business: Tech mining to capture business interests and activities around Big Data. In Big Data and Cloud Computing (BDCloud), Social Computing and Networking (SocialCom), Sustainable Computing and Communications (SustainCom) (BDCloud-SocialCom-SustainCom), 2016 IEEE International Conferences on (pp. 145-150). IEEE.

[17] McAfee, A., Brynjolfsson, E., Davenport, T. H., Patil, D. J., \& Barton, D. (2012). Big data. The management revolution. Harvard Bus Rev, 90(10), 61-67.

[18] Popovič, A., Hackney, R., Tassabehji, R., \& Castelli, M. (2016). The impact of big data analytics on firms' high value business performance. Information Systems Frontiers, 1-14.

[19] Ting Yu, Xia Xue, Jiaqi Liu, Mechanism Design of Health Information Platform Under the Big Data Environment, Science Innovation. Vol. 4, No. 2, 2016, pp. 105-109. doi: 10.11648/j.si.20160402.25

[20] Zhang Hang, Liu Yun, The Research Based on Big Data Management Accounting Model Building, Science Innovation. Vol. 4, No. 4, 2016, pp. 228-234. doi: 10.11648/j.si.20160404.20

[21] Wang Weichen, Gao Jing, Cao Rui. Survey of Big Data Storage Technology. Internet of Things and Cloud Computing. Vol. 4, No. 3, 2016, pp. 28-33. doi: 10.11648/j.iotcc. 20160403.13

[22] Lidong Wang, Cheryl Ann Alexander. Stroke Care and the Role of Big Data in Healthcare and Stroke. Rehabilitation Sciences. Vol. 1, No. 1, 2016, pp. 16-24. doi: 10.11648/j.rs.20160101.13 